\title{
Evaluation of Thymol- $\beta$-D-Glucopyranoside as a Potential Prebiotic Intervention to Reduce Carriage of Zoonotic Pathogens in Weaned and Feeder Pigs
}

\author{
Gizem Levent ${ }^{1,2}{ }^{\oplus}$, Robin C. Anderson ${ }^{1, *}$, Branko Petrujkić ${ }^{1,3}{ }^{\circledR}$, Toni L. Poole ${ }^{1}$, Haiqi He ${ }^{1}$, \\ Kenneth J. Genovese ${ }^{1}$, Michael E. Hume ${ }^{1}$, Ross C. Beier ${ }^{1}{ }^{\circledR}$, Roger B. Harvey ${ }^{1}$ and David J. Nisbet $^{1}$
}

1 United States Department of Agriculture, Agricultural Research Service, Food and Feed Safety Research Unit, College Station, TX 77845, USA; GLevent@cvm.tamu.edu (G.L.); Petrujkic@vet.bg.ac.rs (B.P.); Toni.Poole@usda.gov (T.L.P.); Haiqi.He@usda.gov (H.H.); Kenneth.Genovese@usda.gov (K.J.G.); Michael.Hume@usda.gov (M.E.H.); Ross.Beier@usda.gov (R.C.B.); Roger.Harvey@usda.gov (R.B.H.); David.Nisbet@usda.gov (D.J.N.)

2 Department of Veterinary Pathobiology, Texas A\&M University, College Station, TX 77840, USA

3 Faculty of Veterinary Medicine, University of Belgrade, 11000 Belgrade, Serbia

* Correspondence: robin.anderson@usda.gov; Tel.: +1-979-260-9317

Citation: Levent, G.; Anderson, R.C.; Petrujkić, B.; Poole, T.L.; He, H.; Genovese, K.J.; Hume, M.E.; Beier, R.C.; Harvey, R.B.; Nisbet, D.J. Evaluation of

Thymol- $\beta$-D-Glucopyranoside as a Potential Prebiotic Intervention to Reduce Carriage of Zoonotic Pathogens in Weaned and Feeder Pigs. Microorganisms 2021, 9, 860 . https://doi.org/10.3390/ microorganisms 9040860

Academic Editor: María Teresa Gómez-Muñoz

Received: 1 March 2021

Accepted: 13 April 2021

Published: 16 April 2021

Publisher's Note: MDPI stays neutral with regard to jurisdictional claims in published maps and institutional affiliations.

Copyright: (c) 2021 by the authors. Licensee MDPI, Basel, Switzerland. This article is an open access article distributed under the terms and conditions of the Creative Commons Attribution (CC BY) license (https:// creativecommons.org/licenses/by/ $4.0 /)$.
Abstract: The gut of food-producing animals is a reservoir for foodborne pathogens. Thymol is bactericidal against foodborne pathogens but rapid absorption of thymol from the proximal gut precludes the delivery of effective concentrations to the lower gut where pathogens mainly colonize. Thymol- $\beta$-D-glucopyranoside is reported to be more resistant to absorption than thymol in everted jejunal segments and could potentially function as a prebiotic by resisting degradation and absorption in the proximal gut but being hydrolysable by microbial $\beta$-glycosidase in the distal gut. Previous in vitro studies showed bactericidal effects of thymol- $\beta$-D-glucopyranoside against Campylobacter, Escherichia coli, and Salmonella enterica serovar Typhimurium in the presence but not absence of intestinal microbes expressing $\beta$-glycosidase activity, indicating that hydrolysis was required to obtain antimicrobial activity. Presently, the oral administration of thymol- $\beta$-D-glucopyranoside was studied to examine the effects on intestinal carriage of Campylobacter, E. coli, and S. Typhimurium in swine. The effects of thymol- $\beta$-D-glucopyranoside or thymol on antimicrobial sensitivity of representative $E$. coli isolates and characterized Salmonella strains were also explored. Results from two in vivo studies revealed little antimicrobial effects of thymol- $\beta$-D-glucopyranoside on Campylobacter, E. coli, or $S$. Typhimurium in swine gut. These findings add credence to current thinking that hydrolysis and absorption of thymol- $\beta$-D-glucopyranoside and thymol may be sufficiently rapid within the proximal gut to preclude delivery to the distal gut. Antibiotic susceptibilities of selected bacterial isolates and strains were mainly unaffected by thymol. Further research is warranted to overcome obstacles, preventing the delivery of efficacious amounts of thymol- $\beta$-D-glucopyranoside to the lower gut.

Keywords: Campylobacter; Escherichia coli; Salmonella; swine; thymol; thymol- $\beta$-D-glucopyranoside

\section{Introduction}

Campylobacter and non-typhoidal Salmonella are leading bacterial causes of human foodborne illness that are estimated to cause 1.5 and 1.35 million human infections, respectively, every year in the United States [1,2]. Poultry, swine, and cattle can harbor these pathogens within their digestive tracts and risk contaminating carcasses during processing. In recent years, the increasing number of antibiotic-resistant Campylobacter and Salmonella isolates recovered from human infections has also become a serious public health threat [1]. Antibiotic use in these animals may select for antibiotic resistant bacteria which can result in serious public health consequences [3]. Therefore, a non-antibiotic pre-harvest strategy is needed to reduce the risk of carcass contamination at the abattoir and also to reduce the risk of selection of antibiotic resistant pathogens that can pose a greater risk for public health. 
Essential oils such as thymol are considered attractive alternatives to antibiotics due to their bactericidal activities against a variety of pathogens [4]. Thymol is a component of the essential oil of thyme that exerts its bactericidal activity via insertion into the lipidrich bacterial cell wall and subsequent disintegration of microbial cell wall integrity [5-7]. Thymol has been shown to be effective against zoonotic pathogens such as Salmonella, Campylobacter, as well as against many enterotoxigenic Escherichia coli, such as those responsible for disease in young pigs [8], with minimum inhibitory concentrations against pure cultures ranging from 1.00 and $1.55 \mu \mathrm{mol} / \mathrm{mL}$ [5,7,9]. In addition to its bactericidal activity, thymol has been also shown to increase the sensitivity of pathogens against antibiotics thus acting as a potential solution to combat antibiotic resistance $[10,11]$. Conversely, essential oil extracts from Dittrichia graveolens and rich in oxygenated monoterpenes have been reported to be antagonistic against the antimicrobial activity of streptomycin [12]. Results from in vivo studies, however, have shown marginal antimicrobial activity of free thymol against foodborne pathogens in the gastrointestinal tract of swine due potentially to its rapid absorption or degradation in the stomach and small intestine of monogastric animals [13-15]. A more stable, conjugated form of thymol, thymol- $\beta$-D-glucopyranoside, has recently been investigated as a potential prebiotic to promote the passage of the thymol derivative to the cecum and large intestine [16-19]. Conceptually, it was hypothesized that because of its $\beta$-glycosidic bond and larger size thymol- $\beta$-D-glucopyranoside would be resistant to hydrolysis and absorption in the stomach and the proximal small intestine of monogastric animals yet readily hydrolysable by microbial $\beta$-glycosidases, abundantly expressed by autochthonous bacteria in the distal gut [20,21]. Evidence in support of the hypothesis that thymol- $\beta$-D-glucopyranoside is more resistant to absorption than free thymol was reported by Petrujkić et al. [19] where approximately 2.5 times more free thymol was absorbed by everted porcine jejunal segments than thymol- $\beta$-D-glucopyranoside. Additionally, Epps et al. [17] reported that microbial $\beta$-glycosidase activity expressed by a common gut bacterium, Parabacteroides distasonis, rapidly hydrolyzed thymol- $\beta$-D-glucopyranoside to yield free thymol which was then able to exert potent anti-Campylobacter activity during co-culture with $C$. jejuni and $C$. coli. When cultured alone, and thus in the absence of $\beta$-glycosidase activity, intact thymol- $\beta$-D-glucopyranoside exerted no antimicrobial activity against $C$. jejuni and C. coli.

Epps and colleagues [16] also compared the effects of oral administration of thymol or thymol- $\beta$-D-glucopyranoside (each to achieve approximately $1 \mathrm{mM}$ of luminal concentration) on viable counts of indigenous Campylobacter and E. coli in the crop and ceca of market-aged broilers. They recovered 1.1 to $1.5 \log _{10}$ fewer Campylobacter /g crop content from broilers treated with thymol- $\beta$-D-glucopyranoside compared to thymol-treated or untreated broilers but observed no effect of treatment on the recovery of Campylobacter from the ceca. The authors suggested rapid hydrolysis of thymol- $\beta$-D-glucopyranoside by crop microbiota may have concurrently hastened the absorption of the liberated thymol and depleted effective concentrations of the thymol conjugate thereby preventing efficient passage through the stomach and small intestine [16]. Significant effects of thymol or thymol- $\beta$-D-glucopyranoside were not observed on the recovery of $E$. coli from either crop or cecal contents collected from the broilers, which the authors attributed as potentially being due to a dose too low for this bacterial population [16]. Results from in vitro studies, for instance, revealed that a dose of $1 \mathrm{mM}$ thymol- $\beta$-D-glucopyranoside was effective against Campylobacter [16,17] but doses of 3 and $6 \mathrm{mM}$ thymol- $\beta$-D-glucopyranoside were needed to achieve equivalent activity against Salmonella Typhimurium and E. coli K88 [18] when cultured with intestinal microbiota recovered from chickens or pigs. As predicted, thymol- $\beta$-D-glucopyranoside at such doses exhibited little to no antimicrobial activity against these pathogens when cultured in pure culture due to the absence of appreciable $\beta$-glycosidase activity. Following up on this research, the objectives of the present study were to explore potential in vivo effects of multiple concentrations of $6 \mathrm{mM}$ thymol- $\beta-\mathrm{D}-$ glucopyranoside on experimentally inoculated populations of $S$. Typhimurium population and indigenous E. coli populations in the swine gastrointestinal tract. In addition, to investi- 
gate potential effects of thymol on antibiotic susceptibility, selected wildtype E. coli isolates recovered from the pigs and three characterized Salmonella strains were tested against a panel of antibiotics before and after potential exposure to thymol- $\beta$-D-glucopyranoside or the hydrolyzed aglycone, thymol.

\section{Materials and Methods}

\subsection{Animals, Challenge Salmonella, and Thymol- $\beta$-D-Glucopyranoside}

For in vivo studies, all pigs (male and female progeny of Landrace $x$ Yorkshire dams crossed with Pietrain $x$ Duroc $x$ Hampshire sires) were obtained from a local producer and upon delivery to our facility, were cared for according to a protocol approved by the Southern Plains Agricultural Research Center's Institutional Animal Care and Use Committee (ACUC Protocol \#2104005 approved October 15, 2014). All pigs were found to be culture-negative for the presence of wildtype Salmonella and all pigs in the first study were found to be culture-negative for Campylobacter via qualitative culture of rectal swabs (2/pig) collected upon their arrival to our rearing facility. Qualitative culture for Salmonella was accomplished via pre-enrichment of one of the swabs collected from each pig in tetrathionate broth (Difco, Becton Dickinson, Sparks, MD, USA), secondary enrichment in Rappaport-Vassiliadis broth (Difco), and selective differentiation on novobiocinsupplemented $(25 \mu \mathrm{g} / \mathrm{mL}$ ) Brilliant Green Agar (Oxoid, Unipath Ltd., Basinstoke, Hampshire, England) as previously described [22]. Cultivation of the remaining rectal swab of each pig for wildtype Campylobacter was accomplished by streaking to Campy-Cefex agar prepared and used as described by Stern et al. [23]. Since we had anticipated these pigs to be culture-negative for wildtype Salmonella, a S. Typhimurium (NVSL 95-1776), possessing natural resistance to novobiocin (Nov), and having been made nalidixic acid resistant (Nal) via successive cultivation in tryptic soy broth containing up to $20 \mu \mathrm{g}$ of nalidixic acid/mL [24], was used as an experimental challenge strain in our studies. Inocula for experiments were obtained from $S$. TyphimuriumNovr-Nalr cultures grown $24 \mathrm{~h}$ at $37^{\circ} \mathrm{C}$ in tryptic soy broth (Difco) supplemented with $25 \mu \mathrm{g}$ of novobiocin/mL and $20 \mu \mathrm{g}$ of nalidixic acid/mL. Novobiocin and nalidixic acid were purchased from Sigma-Aldrich (St. Louis, MO, USA); thymol- $\beta$-D-glucopyranoside was purchased from Christof Senn Laboratories, Dielsdorf, Switzerland.

\subsection{In Vivo Study Designs}

In the first pig study, 18 weaned pigs ( $24 \pm 5 \mathrm{~kg}$ live body weight) were orally gavaged with $2 \times 10^{9}$ colony forming units (CFU) of the $S$. TyphimuriumNovr-Nalr approximately $2 \mathrm{~h}$ after arrival (11:00) to the rearing facility and randomly allocated to 6 pens (3 pigs/pen) and twice-treated via oral gavage ( 2 pens/treatment) that same day (16:00 and 21:00) with 0,6 , or $18 \mathrm{mg}$ of thymol- $\beta$-D-glucopyranoside $/ \mathrm{kg}$ body weight. Pigs were provided ad libitum access to water and a non-medicated starter diet prepared by Luedemann Feed \& Farm, (Brenham, TX, USA) composed (weight \%) of 65\% ground corn, $14.1 \%$ soybean meal, 4.8\% lysine, 0.1\% Mycolock NC-500 (Trouw Nutrition USA, Strykersville, NY, USA), and $0.1 \%$ selenium. This was the same diet used by the farm that provided the pigs. Pigs were euthanized $12 \mathrm{~h}$ after the last treatment and cecal and rectal contents collected at necropsy were cultured to enumerate the $S$. TyphimuriumNovr-Nalr and wildtype E. coli and Campylobacter.

In a second pig study, 12,11, and 12 weaned pigs, respectively, averaging $40 \pm 8 \mathrm{~kg}$ live body weight, were randomly allocated to a single day's feed treatment of 0,18 , or $52 \mathrm{mg}$ thymol- $\beta$-D-glucopyranoside/ $\mathrm{kg}$ live body weight. All, except 1 , of the pigs were placed ( 2 per pen) to concrete-floored pens, with the remaining pig placed individually in a similar pen. Pigs were acclimated to water and the commercially-prepared nonmedicated starter diet provided ad libitum via twice-a-day feedings (08:00 and 16:00) for 14 days. On the evening of the 14th day, all pigs were orally inoculated via gavage with approximately $2 \times 10^{9} \mathrm{CFU}$ of the $S$. TyphimuriumNovr-Nalr. Treatments were administered via two feedings (08:00 and 16:00) to each pen on the 15th day via the top 
dressing half of the day's treatment into a $20 \%$ portion of each meal, which was offered first to achieve total consumption of the thymol- $\beta$-D-glucopyranoside. Approximately $30 \mathrm{~min}$ later the remainder of the meal was offered. Pigs not receiving thymol- $\beta$-D-glucopyranoside were fed each meal in two portions likewise. Sixteen $\mathrm{h}$ and again $24 \mathrm{~h}$ after administration of the last meal, one pig from each pen was euthanized and necropsied for collection of cecal and rectal contents so that $n=6,6$, and 6 pigs for 0,18 , and $54 \mathrm{mg} / \mathrm{kg}$ live body weight per day at $16 \mathrm{~h}$ post treatment and $n=6,5$, and 6 for 0,18 , and $54 \mathrm{mg} / \mathrm{kg}$ live body weight per day at $24 \mathrm{~h}$ post treatment, respectively. Gut contents were cultured to enumerate the $S$. TyphimuriumNovr-Nalr and wildtype E. coli and Campylobacter.

\subsection{Bacterial Enumerations}

Gut samples collected from pigs at necropsy were serially diluted (10-fold) in 0.1-M sodium phosphate buffer ( $\mathrm{pH}$ 6.5) and plated on Brilliant Green agar supplemented with $25 \mu \mathrm{g}$ of novobiocin $/ \mathrm{mL}$ and $20 \mu \mathrm{g}$ of nalidixic acid $/ \mathrm{mL}$ and on MacConkey (Difco) agar for viable cell count of the $S$. TyphimuriumNovr-Nalr and generic E. coli, respectively. Samples collected in the second pig study were also plated to Campy Cefex agar for enumeration of generic Campylobacter species. Salmonella TyphimuriumNovr-Nalr and E. coli were counted after $24 \mathrm{~h}$ of aerobic incubation at $37^{\circ} \mathrm{C}$; Campylobacter were enumerated after $48 \mathrm{~h}$ of microaerophilic $\left(\mathrm{N}_{2}: \mathrm{CO}_{2}: \mathrm{O}_{2} ; 85: 10: 5\right)$ incubation at $42{ }^{\circ} \mathrm{C}$.

\subsection{Phenotypic Antibiotic Susceptibility}

An assessment of potential co-selection of increased or decreased antibiotic susceptibility by thymol, the hydrolytic product of thymol- $\beta$-D-glucopyranoside, was performed using randomly chosen strains of presumptive wildtype $E$. coli isolated from rectal swabs of each treatment group of the second in vivo study (18 and $54 \mathrm{mg}$ of thymol- $\beta$ D-glucopyranoside/kg body weight). Rectal swabs were collected from 6 pigs of each treatment group before treatment administration (pre-exposure isolates) and from the same pigs ( 3 pigs/treatment) after $16 \mathrm{~h}$ and again after $24 \mathrm{~h}$ of treatment (3 pigs/treatment) administration (16 h-post exposure and $24 \mathrm{~h}$-post exposure isolates, respectively). The presumptive pre-treatment E. coli were recovered following $24 \mathrm{~h}$ of incubation of MacConkey plates streaked with rectal swabs collected immediately before the first feed administration treatments and presumptive post-treatment $E$. coli were recovered from rectal swabs collected immediately before the euthanasia of the pigs necropsied at 16 and $24 \mathrm{~h}$ post treatment.

Additionally, multi-drug resistant $S$. enterica strains characterized as serovars Give (isolate 24349) and Typhimurium (isolates 22544 and 20731) and graciously provided by Dr. Shaohua Zhao (Office of Research, Center for Veterinary Medicine, Food, and Drug Administration, Laurel, MD. USA) [25] were used to assess potential effects of thymol exposure on antimicrobial sensitivity. These strains, having no known prior exposure to thymol, were chosen to avoid potentially confounding effects associated with the $S$. Typhimurium Novr-Nalr challenge strain which was prominent in post-treatment rectal populations. Phenotypic antibiotic susceptibility of these strains was previously reported by Zhao et al. [25]. To provide sublethal exposure of these Salmonella strains, they were adapted via three consecutive- $24 \mathrm{~h}$ cultures in Thermo Scientific Sensititre ${ }^{\mathrm{TM}}$ Cation Adjusted Mueller-Hinton broth w/TES (Remel Inc., Lenexa, KS, USA) supplemented with $0.5 \mathrm{mM}$ thymol. Isolates before and after thymol exposure were assessed for their phenotypic antibiotic susceptibility.

Antibiotic susceptibility testing of isolates were performed according to CLSI standards [26] against 18 antibiotics (ampicillin, ceftiofur, chlortetracycline, clindamycin, danofloxacin, enrofloxacin, florfenicol, gentamicin, neomycin, oxytetracycline, penicillin, spectinomycin, sulphadimethoxime, tiamulin, tilmicosin, trimethoprim/sulphamethoxazole, tulathromycin, and tylosin tartrate) using the broth microdilution method and Sensititre Bovine/Porcine (BOPO6F) plates and Sensititre system (Trek Diagnostics System, UK). Susceptibilities are reported as minimum inhibitory concentrations (MIC) to allow for comparisons in the absence of antimi- 
crobial resistance breakpoints, which for the antibiotics tested are not available for porcine gastrointestinal isolates reported here. Antimicrobial resistance breakpoints $(S=$ sensitive, $I=$ intermediate, and $\mathrm{R}=$ resistant) corresponding to ampicillin, ceftiofur, gentamicin, and trimethoprim/sulphamethoxazole are available for humans and are (MIC) $\mathrm{S}<8, \mathrm{I}=16, \mathrm{R}>32$; $\mathrm{S}<2$, $\mathrm{I}=4, \mathrm{R}>8 ; \mathrm{S}<4, \mathrm{I}=8, \mathrm{R}>16, \mathrm{~S}<2 / 38, \mathrm{I}=$ not available, and $\mathrm{R}>4 / 76$, respectively [27].

\subsection{Statistical Analysis}

In the first animal study, control and thymol- $\beta$-D-glucopyranoside treatments were administered independently via oral gavage to each pig. Accordingly, $\log _{10}$ transformations of viable counts (CFU/g gut contents) of $S$. TyphimuriumNovr-Nalr and generic E. coli were analyzed for the effects of treatment using an analysis of variance. Polynomial contrasts were used to examine linear and quadratic effects of the treatment level. In the second study, control and thymol- $\beta$-D-glucopyranoside treatments were administered communally to pigs within each pen randomly allocated to receive its respective treatment and then one pig from each pen was collected for necropsy at $16 \mathrm{~h}$ post treatment with the remaining pig in each pen being collected for necropsy $24 \mathrm{~h}$ post treatment. Consequently, each pen served as the experimental unit and viable counts $\left(\log _{10} \mathrm{CFU} / \mathrm{g}\right)$ of $S$. TyphimuriumNovr-Nalr, generic E. coli, and Campylobacter species were analyzed for the main effects of treatment and time using a repeated measures analysis of variance and least significant difference (LSD) separation of means. All statistical analyses were completed with Statistix10 Analytical Software (Tallahassee, FL, USA). Due the availability of too few isolates for antimicrobial susceptibility testing, pre-exposure and post-exposure comparisons of MIC values are presented descriptively without statistical analysis.

\section{Results and Discussion}

\subsection{In Vivo Pig Studies}

Results from two separate animal studies revealed that oral administration of thymol- $\beta$-Dglucopyranoside had little if any effect on concentrations of the Salmonella TyphimuriumNovrNalr orally inoculated into the pigs and likewise had little if any effect on gut concentrations of generic E. coli or Campylobacter species (Tables 1 and 2). In the first study, for instance, cecal but not rectal concentrations of the $S$. TyphimuriumNovr-Nalr were reduced in a linear $(p<0.05)$, dose-dependent fashion by treatment (Table 1). Neither cecal nor rectal concentrations of wildtype E. coli were affected by treatment and Campylobacter were not recovered from any of the pigs of the first study. The absence of a treatment effect on cecal E. coli populations while there was an observed treatment effect on $S$. TyphimuriumNovr-Nalr likely reflects the lower sensitivity of $E$. coli to the bactericidal effect of free thymol. These doses were calculated to deliver, based on an estimated $200 \mathrm{~mL}$ of intestinal volume, a total dose of approximately 2.3 to $6.9 \mu \mathrm{mol}$ of thymol- $\beta$-D-glucopyranoside/g content to the lumen of the pig gut if no absorption were to have occurred. In our second study, which was done to assess the potential impact of an older distal gut flora on the antimicrobial activity of thymol- $\beta$-D-glucopyranoside, we examined the use of two dose levels (similarly calculated, based on an estimated $400 \mathrm{~mL}$ of intestinal volume, to deliver approximately 5.4 to $16.3 \mu \mathrm{mol}$ of thymol- $\beta$-D-glucopyranoside $/ \mathrm{g}$ to the lumen of the pig gut). Additionally, these doses were administered at two intervals to allow the broadening of sampling intervals. Despite the administration of doses equivalent to or approximately 3-fold higher than the dosed used in the first study and longer intervals between the administration of the last dose and sample collection at necropsy, evidence of an efficacious treatment effect was not observed. A treatment effect was observed on rectal $E$. coli populations but in this case rectal contents from pigs treated with $18 \mathrm{mg}$ of thymol- $\beta-\mathrm{D}-$ glucopyranoside/g body weight had higher E. coli populations than pigs not treated or treated with $54 \mathrm{mg}$ of thymol- $\beta$-D-glucopyranoside/g body weight (Table 2). 
Table 1. Effect of oral thymol- $\beta$-D-glucopyranoside treatment on gut novobiocin- and nalidixic acid-resistant Salmonella Typhimurium (S. TyphimuriumNovr-Nalr) and generic E. coli in weaned swine.

\begin{tabular}{cccccc}
\hline \multicolumn{7}{c}{ Thymol- $\beta$-D-Glucopyranoside } \\
Treatment \\
(mg/kg Live Body Weight)
\end{tabular}

Table 2. Effect of oral thymol- $\beta$-D-glucopyranoside treatment on gut novobiocin- and nalidixic acidresistant Salmonella Typhimurium (S. TyphimuriumNovr-Nalr) and generic E. coli and Campylobacter species in weaned swine.

\begin{tabular}{|c|c|c|c|c|c|c|c|c|c|}
\hline & \multicolumn{2}{|c|}{$\begin{array}{l}\text { (mg/kg Live Body } \\
\text { Weight) }\end{array}$} & \multicolumn{3}{|c|}{ Hours Post Treatment } & \multicolumn{3}{|c|}{ Main Effect ( $p$ Values) } & \multirow[b]{2}{*}{ SEM } \\
\hline & None & 18 & 54 & 16 & 24 & Treatment & Time & Interaction & \\
\hline \multicolumn{10}{|c|}{ 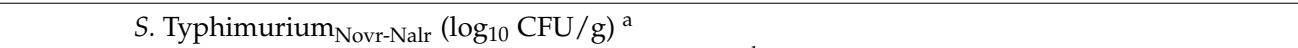 } \\
\hline Cecal & 2.70 & 2.77 & 2.64 & $2.20^{\mathrm{e}}$ & $3.21^{\mathrm{d}}$ & 0.9599 & 0.0291 & 0.8778 & 0.539 \\
\hline Rectal & 2.10 & 2.10 & 1.37 & 2.00 & 1.72 & 0.2692 & 0.4537 & 0.7558 & 0.482 \\
\hline \multicolumn{10}{|c|}{ Escherichia coli $\left(\log _{10} \mathrm{CFU} / \mathrm{g}\right)$} \\
\hline Cecal & 5.29 & 5.88 & 5.37 & 5.26 & 5.77 & 0.2300 & 0.2479 & 0.8596 & 0.549 \\
\hline Rectal & $4.73^{b, c}$ & $5.54^{\mathrm{b}}$ & $4.35^{\mathrm{c}}$ & 5.01 & 4.73 & 0.0100 & 0.3833 & 0.6126 & 0.398 \\
\hline \multicolumn{10}{|c|}{ Campylobacter species $\left(\log _{10} \mathrm{CFU} / \mathrm{g}\right)$} \\
\hline Cecal & 4.04 & 4.13 & 3.52 & 3.67 & 4.13 & 0.2139 & 0.1235 & 0.2652 & 0.368 \\
\hline Rectal & 3.48 & 3.76 & 3.57 & $3.23^{\mathrm{e}}$ & $3.98^{\mathrm{d}}$ & 0.8090 & 0.0150 & 0.3263 & 0.352 \\
\hline
\end{tabular}

a $n=6,6$, and 6 pigs were fed a one-day administration of 0,18 , and $54 \mathrm{mg}$ of thymol- $\beta$-D-glucopyranoside $/ \mathrm{kg}$ live body weight per day via two equal feedings (08:00 and 16:00). Gut samples were collected 16 and $24 \mathrm{~h}$ after the last administration for bacteriological cultivation of cecal and rectal contents collected via necropsy to enumerate the $S$. TyphimuriumNovr-Nalr and wildtype E. coli and Campylobacter species, $b, c$ Treatment means within row with unlike superscript letters differ based on a LSD separation of means $(p<0.05)$, d,e Time of sampling means within row with unlike superscript letters differ based on a LSD separation of means $(p<0.05)$.

The lack of an efficacious effect of thymol- $\beta$-D-glucopyranoside suggests that adequate amounts of thymol- $\beta$-D-glucopyranoside or free thymol were not delivered to the cecum or large intestine. Possible reasons for this could be that hydrolysis of thymol- $\beta-\mathrm{D}-$ glucopyranoside and the subsequent absorption of free thymol may have been sufficiently rapid within the proximal small intestine to preclude the delivery of the intact glucopyranoside to the cecum and large intestine. Results from earlier in vitro incubations indicated that there was indeed appreciable thymol- $\beta$-D-glucopyranoside hydrolytic activity, as evidenced by anti-Salmonella activity, in populations of swine jejunal microbes [28]. Similarly, it is also possible that despite being $>2$-times more resistant to absorption than free thymol in everted jejunal segments [19], appreciable quantities of thymol- $\beta$-D-glucopyranoside administered in the present study may still have been absorbed in the small intestine. Van Noten and colleagues [29], in work published subsequent to the completion of our live animal studies, reported that appreciable amounts of thymol- $\alpha$-D-glucopyranoside or thymol- $\beta$-D-glucopyranoside were hydrolyzed by microbial activity in the proximal gut of pigs. The thymol-conjugates in their study were fed at doses of approximately $42 \mathrm{mg} / \mathrm{kg}$ 
body weight administered over six meals each administered $2 \mathrm{~h}$ apart to pigs similar in weight to those used in our first in vivo study, Van Noten et al. [29] further suggested that neither glucopyranoside was completely resistant from absorption in the stomach or to further hydrolysis and absorption in the small intestine, with only traces, if any, of the glucopyranosides or free thymol being recovered in the small intestine or more distal portions of the intestinal tract [29]. Based on their analysis, Van Noten et al. [29] concluded that in the absence of absorption the maximal amounts of thymol and thymol- $\alpha$-D-glucopyranoside expected to reach the small intestine would be approximately $0.3 \mu \mathrm{mol} / \mathrm{g}$ digesta. Their results further indicated that thymol- $\beta$-D-glucopyranoside may be absorbed more rapidly in the stomach than thymol- $\alpha$-D-glucopyranoside thus indicating even lesser amounts of thymol- $\beta$-D-glucopyranoside would pass to the small intestine. Results from our study add credence to their suggestion that rapid hydrolysis of thymol- $\beta$-D-glucopyranoside likely precludes the delivery of the conjugate to the lower gut. For instance, based on the results of Van Noten et al. [29] it is likely that appreciable amounts of the 18 or $54 \mathrm{mg}$ of thymol- $\beta$-D-glucopyranoside/body weight administered in the feed in our second study would be hydrolyzed. Subsequent absorption of the liberated thymol thus would have precluded the delivery of thymol- $\beta$-D-glucopyranoside at or above the 1,3 , and $6 \mu \mathrm{mol} / \mathrm{g}$ of gut content, respectively, reported to achieve effective antimicrobial activity against Campylobacter, Salmonella, and E. coli in vitro [16-18]. Contrarily, our observed effect of $18 \mathrm{mg}$ of thymol- $\beta$-D-glucopyranoside $/ \mathrm{kg}$ body weight on cecal $S$. TyphimuriumNovrNalr in our first study, achieving a $1.75 \log _{10}$-fold decrease in viable counts, may reflect differences due to the method of administrations used in the two studies. For instance, experimental administration of treatments via oral gavage of a liquid-based treatment, while not practical in production settings, likely promoted more rapid passage of the intact glucopyranoside through the stomach and small intestine than feed administration. Subsequent retention within the cecum would be expected to persist longer than in the stomach and small intestine and hydrolysis of thymol- $\beta$-D-glucopyranoside by gut microbes therein would liberate free thymol, thereby allowing opportunity to act on Salmonella residing in this site.

It is possible, however, that uptake and internal compartmentalization of thymol- $\beta$ D-glucopyranoside by gut bacteria, or the lipophilic properties of both thymol and, albeit to a lesser extent, thymol- $\beta$-D-glucopyranoside, may sequester these compounds away from hydrolytic enzymes thus preventing the release of free thymol. Evidence for the former mechanism has been reported by Beier et al. [30] who found that rapid bacterial uptake of thymol- $\beta$-D-glucopyranoside can occur. In the case of the latter mechanism, results from in vitro studies, for instance, indicated that lipids and fatty acids inhibited the bactericidal activity of thymol- $\beta$-D-glucopyranoside in mixed populations of gut bacteria, thus implicating a potential role of the lipophilicity of both thymol and thymol- $\beta$-Dglucopyranoside [31].

Considering that mean retention times of digesta passage through the pig stomach, small intestine and total tract are estimated to be 1, 4, and more than $30 \mathrm{~h}$, respectively [32], it may be possible to feed higher oral doses of thymol- $\beta$-D-glucopyranoside than those used here or by Van Noten et al. [29] to avoid complete hydrolysis of the administered doses in the stomach and small intestine yet persist long enough to reach the distal gut to exert antimicrobial activity against zoonotic pathogens upon activation by microbial thymol- $\beta$-D-glucopyranoside-hydrolyzing enzymes. Alternatively, it may be possible to use glucopyranoside compounds synthesized with disaccharides or other larger molecular weight carbohydrate moieties that may be more resistant to hydrolysis and absorption in the proximal gut. Additional research is currently underway to try and overcome these possible obstacles.

\subsection{Antimicrobial Susceptibilities}

Results from tests assessing the potential for thymol exposure to co-select for presumptive E. coli isolated from the pigs before and after being fed 18 or $54 \mathrm{mg}$ of thymol- $\beta$-D- 
glucopyranoside/ $\mathrm{kg}$ body weight exhibiting increased or decreased susceptibility to antibiotics included on Sensititre Bovine/Porcine (BOPO6F) plates are presented in Tables 3-5. The results provided limited evidence that prior exposure to thymol- $\beta$-D-glucopyranoside, and potentially its hydrolysis product thymol, may co-select for increased or decreased susceptibility to the antibiotics tested. In most cases, changes in antibiotic resistance profiles were not observed between the presumptive $E$. coli isolates having had no prior exposure or having been previously exposed to thymol- $\beta$-D-glucopyranoside.

We were able to detect the potential for at least 4 -fold or greater increases in MIC values corresponding to ampicillin and ceftiofur in presumptive E. coli recovered from pigs fed $18 \mathrm{mg}$ of thymol- $\beta$-D-glucopyranoside/ $\mathrm{kg}$ body weight (post-exposure) when compared to presumptive E. coli recovered from the same pigs before exposure to thymol$\beta$-D-glucopyranoside (pre-exposure) (Table 3).

Similarly, in comparisons between presumptive E. coli isolates recovered from pigs after or before being fed $52 \mathrm{mg}$ of thymol- $\beta$-D-glucopyranoside/ $\mathrm{kg}$ body weight (postand pre-exposure, respectively), we detected the potential for at least 4 -fold or greater increases in MIC values to ampicillin, ceftiofur, as well as to danofloxacin, enrofloxacin, spectinomycin, and tulathromycin. Conversely, we observed decreased susceptibility of at least 4-fold for oxytetracycline, neomycin, tulathromycin, and spectinomycin in postexposed presumptive E. coli isolates compared to their corresponding pre-exposed isolates (Table 4). In a number of instances, results for increased or decreased susceptibility were undiscernible due to at least one MIC value being unrestrictedly greater or lesser than the pre- or post-exposure comparison (Tables 3 and 4 ).

Of the three multi-drug resistant Salmonella strains tested before or after repeated exposure to sublethal amounts of thymol, which is the active agent of thymol- $\beta$-D-glucopyranoside, we observed no differences in MIC values pre- or post-thymol exposure (Table 5). It is important, however, to recognize that increases of 2- to 4-fold are not necessarily remarkable as these may well be within the variability of the study method and thus may not reflect consequential effects of thymol- $\beta$-D-glucopyranoside or its hydrolysis product thymol.

Table 3. Antimicrobial susceptibilities of presumptive E. coli isolated from rectal swabs of pigs before or after feed administration of $18 \mathrm{mg}$ of thymol- $\beta$-D-glucopyranoside $/ \mathrm{kg}$ body weight.

\begin{tabular}{|c|c|c|c|c|c|c|c|c|c|c|c|}
\hline \multirow[b]{3}{*}{$\underset{\text { a }}{\text { Antibiotic }}$} & \multicolumn{6}{|c|}{$\begin{array}{l}\text { Presumptive E. coli Isolates Recovered Before (Pre-) and } 16 \text { h After } \\
\text { (Post-) Treatment }\end{array}$} & \multicolumn{5}{|c|}{$\begin{array}{l}\text { Presumptive E. coli Isolates Recovered Before (Pre-) and } \\
24 \mathrm{~h} \text { After (Post-) Treatment }\end{array}$} \\
\hline & \multicolumn{2}{|c|}{ Pen 1} & \multicolumn{2}{|c|}{ Pen 3} & \multicolumn{2}{|c|}{ Pen 14} & \multirow{2}{*}{$\begin{array}{c}\text { Pen } 1 \\
\begin{array}{c}\text { Post- } \\
\text { Exposure }\end{array}\end{array}$} & \multicolumn{2}{|c|}{ Pen 3} & \multicolumn{2}{|c|}{ Pen 14} \\
\hline & $\begin{array}{l}\text { Pre- } \\
\text { Exposure }\end{array}$ & $\begin{array}{l}\text { Post- } \\
\text { Exposure }\end{array}$ & $\begin{array}{l}\text { Pre- } \\
\text { Exposure }\end{array}$ & $\begin{array}{l}\text { Post- } \\
\text { Exposure }\end{array}$ & $\begin{array}{l}\text { Pre- } \\
\text { Exposure }\end{array}$ & $\begin{array}{l}\text { Pre- } \\
\text { Exposure }\end{array}$ & & $\begin{array}{l}\text { Pre- } \\
\text { Exposure }\end{array}$ & $\begin{array}{l}\text { Post- } \\
\text { Exposure }\end{array}$ & $\begin{array}{l}\text { Pre- } \\
\text { Exposure }\end{array}$ & $\begin{array}{l}\text { Post- } \\
\text { Exposure }\end{array}$ \\
\hline AMP & 4 & 2 & 1 & 2 & 4 & 4 & 4 & 1 & $4^{b}$ & 2 & 2 \\
\hline XNL & $\leq 0.25$ & $\leq 0.25$ & $\leq 0.25$ & $1^{b}$ & 0.5 & 0.5 & 0.5 & $\leq 0.25$ & $0.5^{c}$ & $\leq 0.25$ & $0.5^{c}$ \\
\hline CTET & $>8$ & $>8$ & $>8$ & $>8$ & $>8$ & $>8$ & $>8$ & $>8$ & $>8$ & $>8$ & $>8$ \\
\hline DANO & $\leq 0.12$ & $\leq 0.12$ & $\leq 0.12$ & $\leq 0.12$ & $\leq 0.12$ & $\leq 0.12$ & $\leq 0.12$ & $\leq 0.12$ & $\leq 0.12$ & $\leq 0.12$ & $\leq 0.12$ \\
\hline ENRO & $\leq 0.12$ & $\leq 0.12$ & $\leq 0.12$ & $\leq 0.12$ & $\leq 0.12$ & $\leq 0.12$ & $\leq 0.12$ & $\leq 0.12$ & $\leq 0.12$ & $\leq 0.12$ & $\leq 0.12$ \\
\hline FFN & 4 & 8 & 8 & 8 & 4 & 4 & 4 & 8 & 4 & 4 & 8 \\
\hline NEO & $\leq 4$ & $\leq 4$ & $\leq 4$ & $\leq 4$ & $\leq 4$ & $\leq 4$ & $\leq 4$ & $\leq 4$ & $\leq 4$ & $\leq 4$ & $\leq 4$ \\
\hline OXY & $>8$ & $>8$ & $>8$ & $>8$ & $>8$ & $>8$ & $>8$ & $>8$ & $>8$ & $>8$ & $>8$ \\
\hline PEN & $>8$ & $>8$ & $>8$ & $>8$ & $>8$ & $>8$ & $>8$ & 8 & $>8$ & $>8$ & $>8$ \\
\hline SPE & 32 & $>64$ & 16 & $>64$ & 16 & 16 & 16 & 16 & 16 & 16 & 16 \\
\hline SDM & $\leq 256$ & $>256^{c}$ & $>256$ & $>256$ & $\leq 256$ & $\leq 256$ & $>256^{c}$ & $>256$ & $\leq 256^{c}$ & $<256$ & $\leq 256^{c}$ \\
\hline TIL & 64 & 64 & 64 & 64 & 64 & $>64$ & 64 & 32 & 64 & 64 & 64 \\
\hline TUL & 4 & 4 & 4 & 8 & 8 & 8 & 4 & 2 & 4 & 4 & 4 \\
\hline
\end{tabular}

a AMP, ampicillin; XNL, ceftiofur; CTET, chlortetracycline; DANO, danofloxacin; ENRO, enrofloxacin; FFN, florfenicol; NEO, neomycin; OXY, oxytetracycline; PEN, penicillin; SPE, spectinomycin; SDM, sulfadimethoxine; TIL, tilmicosin; and TUL, tulathromycin. MIC values for clindamycin; gentamicin; tiamulin, trimethoprim/sulfamethoxazolem and tylosin tartrate were for all isolates $>16, \leq 1,>32, \leq 2$, and $>$ 32 , respectively. ${ }^{\mathrm{b}}$ Presumptive $E$. coli isolates recovered from same pen with post-thymol- $\beta$-D-glucopyranoside exposure MIC values at least 4-fold greater than the corresponding pre-thymol- $\beta$-D-glucopyranoside exposure MIC values. ${ }^{c}$ Undiscernable comparison result due to at least one MIC value being unrestrictedly lesser or greater than the corresponding value. 
Table 4. Antimicrobial susceptibilities of presumptive E. coli isolated from rectal swabs of pigs before or after feed administration of $54 \mathrm{mg}$ of thymol- $\beta$-D-glucopyranoside $/ \mathrm{kg}$ body weight.

\begin{tabular}{|c|c|c|c|c|c|c|c|c|c|c|c|c|}
\hline \multirow[b]{3}{*}{$\underset{\text { a }}{\text { Antibiotic }}$} & \multirow[b]{3}{*}{$\begin{array}{l}\text { Pre- } \\
\text { Exposure }\end{array}$} & \multicolumn{5}{|c|}{$\begin{array}{c}\text { Presumptive } E \text {. coli } \text { Isolates Recovered Before (Pre-) } \\
\text { and } 16 \text { h After (Post-) Treatment }\end{array}$} & \multicolumn{6}{|c|}{$\begin{array}{c}\text { Presumptive E. coli } \text { Isolates Recovered Before (Pre-) and } 24 \mathrm{~h} \\
\text { After (Post-) Treatment }\end{array}$} \\
\hline & & \multirow{2}{*}{$\begin{array}{c}\text { Pen } 5 \\
\begin{array}{c}\text { Post- } \\
\text { Exposure }\end{array}\end{array}$} & \multicolumn{2}{|c|}{ Pen 8} & \multicolumn{2}{|c|}{ Pen 10} & \multicolumn{2}{|c|}{ Pen 5} & \multicolumn{2}{|c|}{ Pen 8} & \multicolumn{2}{|c|}{ Pen 10} \\
\hline & & & $\begin{array}{l}\text { Pre- } \\
\text { Exposure }\end{array}$ & $\begin{array}{l}\text { Post- } \\
\text { Exposure }\end{array}$ & $\begin{array}{l}\text { Pre- } \\
\text { Exposure }\end{array}$ & $\begin{array}{l}\text { Post- } \\
\text { Exposure }\end{array}$ & $\begin{array}{l}\text { Pre- } \\
\text { Exposure }\end{array}$ & $\begin{array}{l}\text { Post- } \\
\text { Exposure }\end{array}$ & $\begin{array}{l}\text { Pre- } \\
\text { Exposure }\end{array}$ & $\begin{array}{l}\text { Post- } \\
\text { Exposure }\end{array}$ & $\begin{array}{l}\text { Pre- } \\
\text { Exposure }\end{array}$ & $\begin{array}{l}\text { Post- } \\
\text { Exposure }\end{array}$ \\
\hline AMP & 4 & 4 & 4 & $>16^{\mathrm{b}}$ & 4 & 2 & 4 & 2 & 2 & 1 & 2 & $8^{b}$ \\
\hline XNL & 0.5 & 0.5 & 0.5 & $\leq 0.25^{\mathrm{c}}$ & 0.5 & $\leq 0.25^{c}$ & 0.5 & $\leq 0.25^{\mathrm{c}}$ & 0.5 & 1 & $\leq 0.25$ & $8^{b}$ \\
\hline CTET & $>8$ & $>8$ & $>8$ & $>8$ & $>8$ & $>8$ & $>8$ & $>8$ & $>8$ & 4 & $>8$ & 4 \\
\hline DANO & $\leq 0.12$ & $\leq 0.12$ & $\leq 0.12$ & $\leq 0.12$ & $\leq 0.12$ & $\leq 0.12$ & $\leq 0.12$ & $\leq 0.12$ & $\leq 0.12$ & $0.5^{b}$ & $\leq 0.12$ & $\leq 0.12$ \\
\hline ENRO & $\leq 0.12$ & $\leq 0.12$ & $\leq 0.12$ & $\leq 0.12$ & $\leq 0.12$ & $\leq 0.12$ & $\leq 0.12$ & $\leq 0.12$ & $\leq 0.12$ & $0.5^{b}$ & $\leq 0.12$ & $\leq 0.12$ \\
\hline FFN & 4 & 4 & 4 & 4 & 4 & 8 & 4 & 4 & 8 & 4 & 8 & 4 \\
\hline NEO & $\leq 4$ & $\leq 4$ & $\leq 4$ & $\leq 4$ & 32 & $\leq 4^{b}$ & $\leq 4$ & $\leq 4$ & $\leq 4$ & $\leq 4$ & $\leq 4$ & $\leq 4$ \\
\hline OXY & $>8$ & $>8$ & $>8$ & $>8$ & $>8$ & $>8$ & $>8$ & $>8$ & $>8$ & $2^{b}$ & $>8$ & $2^{b}$ \\
\hline PEN & $>8$ & $>8$ & $>8$ & $>8$ & $>8$ & $>8$ & $>8$ & $>8$ & $>8$ & 8 & $>8$ & $>8$ \\
\hline SPE & 16 & 16 & 16 & 16 & 16 & $>64^{b}$ & 16 & 16 & $>64$ & 64 & $>64$ & $16^{b}$ \\
\hline SDM & $\leq 256$ & $>256^{c}$ & $\leq 256$ & $\leq 256$ & $>256$ & $>256$ & $>256$ & $\leq 256$ & $>256$ & $>256$ & $>256$ & $\leq 256^{c}$ \\
\hline TIL & 64 & 64 & 64 & 64 & $>64$ & 64 & 64 & 64 & 64 & $>64$ & 64 & $>64^{c}$ \\
\hline TUL & 4 & 4 & 4 & 4 & 16 & $4^{\mathrm{d}}$ & 4 & 4 & 8 & 8 & 4 & $16^{b}$ \\
\hline
\end{tabular}

a AMP, ampicillin; XNL, ceftiofur; CTET, chlortetracycline; DANO, danofloxacin; ENRO, enrofloxacin; FFN, florfenicol; NEO, neomycin; OXY, oxytetracycline; PEN, penicillin; SPE, spectinomycin; SDM, sulfadimethoxine; TIL, tilmicosin; TUL, tulathromycin. MIC values for clindamycin; gentamicin; tiamulin, trimethoprim/sulfamethoxazolem, and tylosin tartrate were for all isolates $>16, \leq 1,>32, \leq 2$, and $>$ 32 , respectively. ${ }^{b}$ Presumptive $E$. coli isolates recovered from same pen with post-thymol- $\beta$-D-glucopyranoside exposure MIC values at least 4-fold greater or lesser than the corresponding pre-thymol- $\beta$-D-glucopyranoside exposure MIC values. ${ }^{c}$ Undiscernable comparison due to at least one MIC value being unrestrictedly lesser or greater than the corresponding value.

Table 5. Antimicrobial resistance profiles of stock multidrug resistant Salmonella enterica isolates provided by the US-FDA before and after intentional exposure to $0.5 \mathrm{mM}$ of thymol.

\begin{tabular}{|c|c|c|c|c|c|c|}
\hline & \multicolumn{6}{|c|}{ Salmonella enterica Serovar Before (Pre-) and After (Post-) Repeated Exposure to $0.5 \mathrm{mM}$ of Thymol } \\
\hline & Pre-Exposure & Post-Exposure & Pre-Exposure & Post-Exposure & Pre-Exposure & Post-Exposure \\
\hline \multirow{2}{*}{ Antibiotic $^{a}$} & Give & Give & Typhimurium & Typhimurium & Typhimurium & Typhimurium \\
\hline & 24349 & 24349 & 22544 & 22544 & 20731 & 20731 \\
\hline AMP & 1 & 1 & $>16$ & $>16$ & $>16$ & $>16$ \\
\hline XNL & 0.5 & 0.5 & 1 & 0.5 & $>8$ & $>8$ \\
\hline CTET & $>8$ & $>8$ & $>8$ & $>8$ & $>8$ & $>8$ \\
\hline DANO & $\leq 0.12$ & $\leq 0.12$ & $\leq 0.12$ & $\leq 0.12$ & $\leq 0.12$ & $\leq 0.12$ \\
\hline ENRO & $\leq 0.12$ & $\leq 0.12$ & $\leq 0.12$ & $\leq 0.12$ & $\leq 0.12$ & $\leq 0.12$ \\
\hline FFN & 2 & 2 & 4 & 4 & 8 & 8 \\
\hline NEO & $\leq 4$ & $\leq 4$ & $\leq 4$ & $\leq 4$ & 32 & 32 \\
\hline OXY & $>8$ & $>8$ & $>8$ & $>8$ & $>8$ & $>8$ \\
\hline PEN & 8 & 8 & $>8$ & $>8$ & $>8$ & $>8$ \\
\hline SPE & 32 & 32 & 32 & 32 & $>64$ & $>64$ \\
\hline SDM & $>256$ & $>256$ & $>256$ & $>256$ & $>256$ & $>256$ \\
\hline TIL & $>64$ & $>64$ & $>64$ & $>64$ & $>64$ & $>64$ \\
\hline SXT & $\leq 2$ & $\leq 2$ & $\leq 2$ & $>2^{b}$ & $\leq 2$ & $\leq 2$ \\
\hline TUL & 4 & 8 & 64 & 64 & 16 & 16 \\
\hline
\end{tabular}

a AMP, ampicillin; XNL, ceftiofur; CTET, chlortetracycline; DANO, danofloxacin; ENRO, enrofloxacin; FFN, florfenicol; NEO, neomycin; OXY, oxytetracycline; PEN, penicillin; SPE, spectinomycin; SDM, sulfadimethoxine; TIL, tilmicosin; SXT, trimethoprim/sulfamethoxazole; and TUL, tulathromycin. MIC values for clindamycin; gentamicin; tiamulin and tylosin tartrate were for all isolates $>16, \leq 1,>32$, and $>32$, respectively. ${ }^{\mathrm{b}}$ Undiscernable comparison result due to at least one MIC value being unrestrictedly lesser or greater than the corresponding value.

\section{Conclusions}

The gut of pigs can be colonized with important foodborne and disease-causing bacteria such as Campylobacter, E. coli, and Salmonella. New treatments and strategies are sought to reduce the carriage of these bacteria particularly as they are shipped to the processing plant. Thymol is an attractive candidate to be developed into an antibiotic alternative for swine because it is a natural product and thus likely to be viewed favorably 
by regulatory agencies. Thymol is known to exhibit potent antimicrobial activity against Campylobacter, E. coli, and Salmonella in the laboratory but its effectiveness when fed to animals is modest and inconsistent. This is because thymol is very rapidly absorbed in the proximal gastrointestinal tract, which consequently prevents it from arriving to the cecum and large intestine where these pathogenic bacteria primarily reside. In the present report, we tested a conjugated form of thymol, thymol- $\beta$-D-glucopyranoside, for its potential bypass absorption in the stomach and small intestine and make its way to the cecum and large intestine. Results from live animal studies revealed a modest $\left(1.75 \log _{10}\right.$-fold decrease) decrease in viable counts of an experimentally inoculated $S$. Typhimurium in weaned pigs orally gavaged with $18 \mathrm{mg}$ of thymol- $\beta$-D-glucopyranoside $/ \mathrm{kg}$ body weight but no decrease in wildtype E. coli counts. Feed administration of up to $54 \mathrm{mg}$ thymol- $\beta$ D-glucopyranoside/ $\mathrm{kg}$ body weight was not efficacious in decreasing counts of wildtype Campylobacter, E. coli, or the challenge $S$. Typhimurium strain. The lack of efficacy is likely because hydrolysis and absorption of thymol- $\beta$-D-glucopyranoside and its hydrolysis product, free thymol, may still have been rapid enough within the proximal small intestine to preclude their delivery to the cecum and large intestine. A comparison of antimicrobial resistance profiles between presumptive E. coli isolates or multidrug resistant Salmonella strains provided no evidence that exposure to thymol- $\beta$-D-glucopyranoside or thymol co-selected for strains were more or less susceptible to antibiotics. Additional research is currently underway to try and learn how to overcome obstacles preventing the efficacious activity of thymol- $\beta$-D-glucopyranoside to the lower gastrointestinal tract.

Author Contributions: Conceptualization, R.C.A. and B.P.; methodology, R.C.A.; G.L., B.P., H.H., K.J.G., R.C.B., and R.B.H.; formal analysis, G.L., R.C.A., B.P., T.L.P., H.H., K.J.G., M.E.H., R.C.B., R.B.H., and D.J.N.; investigation, G.L., R.C.A., B.P., T.L.P., H.H., K.J.G., M.E.H., R.C.B., and R.B.H.; resources, R.C.A., D.J.N.; writing-original draft preparation, G.L., R.C.A., T.L.P., M.E.H., R.C.B., and R.B.H.; writing-review and editing, G.L., R.C.A., T.L.P., H.H., K.J.G., M.E.H., R.C.B., and R.B.H.; supervision, R.C.A., D.J.N.; project administration, R.C.A., D.J.N.; funding acquisition, R.C.A. All authors have read and agreed to the published version of the manuscript.

Funding: This project was funded in part by National Pork Board Grant 14-077 and by research funds appropriated by the United States Department of Agriculture.

Institutional Review Board Statement: All animals were cared for according to a protocol approved by the Southern Plains Agricultural Research Center's Institutional Animal Care and Use Committee (ACUC Protocol \#2104005 approved 15 October 2014).

Informed Consent Statement: Not applicable.

Data Availability Statement: Not applicable.

Acknowledgments: We thank Jackie Kotzur and Emily Northcliff for their excellent technical assistance.

Conflicts of Interest: The authors declare no conflict of interest.

\section{References}

1. Centers for Disease Control. Antibiotic Resistance Threats in the United States. Centers for Disease Control and Prevention; U.S. Department of Health and Human Services: Atlanta, GA, USA, 2019. [CrossRef]

2. Scallan, E.; Hoekstra, R.M.; Angulo, F.J.; Tauxe, R.V.; Widdowson, M.; Roy, S.L.; Jones, J.J.; Griffin, P.M. Foodborne illness acquired in the United States-major pathogens. Emerg. Infect. Dis. 2011, 17, 7-15. [CrossRef]

3. Angulo, F.G.; Nunnery, J.A.; Bair, H.D. Antimicrobial resistance in zoonotic enteric pathogens. Rev. Sci. Tech. 2004, $23,485-496$. [CrossRef]

4. Mith, H.; Duré, R.; Delcenserie, V.; Zhiri, A.; Daube, G.; Clinquart, A. Antimicrobial activities of commercial essential oils and their components against food-borne pathogens and food spoilage bacteria. Food Sci. Nutr. 2014, 2, 403-416. [CrossRef]

5. Burt, S. Essential oils: Their antibacterial properties and potential applications in foods-A review. Int. J. Food Microbiol. 2004, 94, 223-253. [CrossRef]

6. Varel, V.H.; Miller, D.N. Effect of antimicrobial agents on livestock waste emissions. Curr. Microbiol. 2000, 40, 392-397. [CrossRef] 
7. Gómez-García, M.; Argüello, H.; Puente, H.; Mencía-Ares, Ó.; González, S.; Miranda, R.; Rubio, P.; Carvajal, A. In-depth in vitro evaluation of the activity and mechanisms of action of organic acids and essential oils against swine enteropathogenic bacteria. Front. Vet. Sci. 2020, 7, 572947. [CrossRef]

8. Fairbrother, J.M.; Nadeau, E.; Gyles, C.L. Escherichia coli in postweaning diarrhea in pigs: An update on bacterial types, pathogenesis, and prevention strategies. Anim. Health Res. Rev. 2005, 6, 17-39. [CrossRef]

9. Anderson, R.C.; Krueger, N.A.; Byrd, J.A.; Harvey, R.B.; Callaway, T.R.; Edrington, T.S.; Nisbet, D.J. Effects of thymol and diphenyliodonium chloride against Campylobacter spp. during pure and mixed culture in vitro. J. Appl. Microbiol. 2009, 107, 1258-1268. [CrossRef]

10. Johny, A.K.; Hoagland, T.; Venkitanarayanan, K. Effect of subinhibitory concentrations of plant-derived molecules in increasing the sensitivity of multidrug-resistant Salmonella enterica Serovar Typhimurium DT104 to antibiotics. Foodborne Path. Dis. 2010, 7, 1165-1170. [CrossRef]

11. Palaniappan, K.; Holley, R.A. Use of natural antimicrobials to increase antibiotic susceptibility of drug resistant bacteria. Inter. J. Food Microbiol. 2010, 140, 164-168. [CrossRef]

12. Miladinović, D.L.; Ilić, B.S.; Kocić, B.D.; Marković, M.S.; Miladinović, L.C. In Vitro trials of Dittrichia graveolens essential oil combined with antibiotics. Nat. Prod. Comm. 2016, 11, 865-868. [CrossRef]

13. Anderson, R.C.; Krueger, N.A.; Genovese, K.J.; Stanton, T.B.; MacKinnon, K.M.; Harvey, R.B.; Edrington, T.S.; Callaway, T.R.; Nisbet, D.J. Effect of thymol or diphenyliodonium chloride on performance, gut fermentation characteristics, and Campylobacter colonization in growing swine. J. Food Prot. 2012, 75, 758-761. [CrossRef]

14. Michiels, J.; Missotten, J.; Dierick, N.; Fremaut, D.; Maene, P.; De Smet, S. In vitro degradation and in vivo passage kinetics of carvacrol, thymol, eugenol and trans-cinnamaldehyde along the gastrointestinal tract of piglets. J. Sci. Food Agric. 2008, 88, 2371-2378. [CrossRef]

15. Michiels, J.; Missotten, J.; Van Hoorick, A.; Ovyn, A.; Fremaut, D.; De Smet, S.; Dierick, N. Effects of dose and formulation of carvacrol and thymol on bacteria and some functional traits of the gut in piglets after weaning. Arch. Anim. Nutr. 2010, 64, 136-154. [CrossRef]

16. Epps, S.V.R.; Harvey, R.B.; Byrd, J.A.; Petrujkić, B.T.; Sedej, I.; Beier, R.C.; Phillips, T.D.; Hume, M.E.; Anderson, R.C.; Nisbet, D.J. Comparative effect of thymol or its glucose conjugate, thymol- $\beta-D-$ glucopyranoside, on Campylobacter in avian gut contents. J. Environ. Sci. Health B 2015, 50, 55-61. [CrossRef]

17. Epps, S.V.R.; Petrujkić, B.T.; Sedej, I.; Krueger, N.A.; Harvey, R.B.; Beier, R.C.; Stanton, T.B.; Phillips, T.D.; Anderson, R.C.; Nisbet, D.J. Comparison of anti-Campylobacter activity of free thymol and thymol- $\beta$-D-glucopyranoside in absence or presence of $\beta$-glycoside-hydrolysing gut bacteria. Food Chem. 2015, 173, 92-98. [CrossRef]

18. Levent, G.; Harvey, R.B.; Ciftcioglu, G.; Beier, R.C.; Genovese, K.J.; He, H.L.; Anderson, R.C.; Nisbet, D.J. In Vitro effects of thymol- $\beta$-D-glucopyranoside on Salmonella enterica serovar Typhimurium and Escherichia coli K88. J. Food Prot. 2016, 79, $299-303$. [CrossRef]

19. Petrujkić, B.T.; Sedej, I.; Beier, R.C.; Anderson, R.C.; Harvey, R.B.; Epps, S.V.R.; Stipanovic, R.D.; Krueger, N.A.; Nisbet, D.J. Ex vivo absorption of thymol and thymol- $\beta$-D-glucopyranoside in piglet everted jejunal segments. J. Agric. Food Chem. 2013, 61, 3757-3762. [CrossRef]

20. Flint, H.; Bayer, E.; Rincon, M.; Lamed, R.; White, B.A. Polysaccharide utilization by gut bacteria: Potential for new insights from genomic analysis. Nat. Rev. Microbiol. 2008, 6, 121-131. [CrossRef]

21. Hamakar, B.R.; Tuncil, Y.E. A perspective on the complexity of dietary fiber structures and their potential effect on the gut microbiota. J. Mol. Biol. 2014, 426, 3838-3850. [CrossRef]

22. Anderson, R.C.; Genovese, K.J.; Harvey, R.B.; Stanker, L.H.; DeLoach, J.R.; Nisbet, D.J. Assessment of the long-term shedding pattern of Salmonella serovar choleraesuis following experimental infection of neonatal piglets. J. Vet. Diagn. Investig. 2000, 12, 257-260. [CrossRef]

23. Stern, N.J.; Wojton, B.; Kwiate, K. A differential selective medium, and dry-ice generated atmosphere for recovery of Campylobacter jejuni. J. Food Prot. 1992, 55, 514-517. [CrossRef]

24. Anderson, R.C.; Jung, Y.S.; Oliver, C.E.; Horrocks, S.M.; Genovese, K.J.; Harvey, R.B.; Callaway, T.R.; Edrington, T.S.; Nisbet, D.J. Effects of nitrate or nitro supplementation, with or without added chlorate, on Salmonella enterica serovar Typhimurium and Escherichia coli in swine feces. J. Food Prot. 2007, 70, 308-315. [CrossRef]

25. Zhoa, S.; McDermott, P.F.; White, D.G.; Qaiyumi, S.; Friedman, S.L.; Abbott, J.W.; Glenn, A.; Ayers, S.L.; Post, K.W.; Fales, W.H.; et al. Characterization of multidrug resistant Salmonella recovered from diseased animals. Vet. Microbiol. 2007, 123, 122-132. [CrossRef]

26. Clinical and Laboratory Standards Institute. M07 Methods for Dilution Antimicrobial Susceptibility Tests for Bacteria That Grow Aerobically, 11th ed.; Wayne, P.A., Ed.; Clinical Laboratory Standards Institute: Wayne, PA, USA, 2018.

27. Clinical and Laboratory Standards Institute. Performance Standards for Antimicrobial Disk and Dilution Susceptibility Tests for Bacteria Isolated from Animals, 4th ed.; CLSI Document VET08; Wayne, P.A., Ed.; Clinical Laboratory Standards Institute: Wayne, PA, USA, 2018.

28. Levant, G.; Ciftcioglu, G.; Anderson, R.C.; Beier, R.C.; Nisbet, D.J. Anti-Salmonella effect of thymol- $\beta$-D-glucopyranoside in porcine jejunal, cecal, and rectal gut contents. In Proceedings of the Abstracts of the 2015 Congress on Gastrointestinal Function, Chicago, IL, USA, 13-15 April 2015; pp. 54-55. 
29. Van Noten, N.; Van Liefferinge, E.; Degroote, J.; De Smet, S.; Desmet, T.; Michiels, J. Fate of thymol and its monoglucosides in the gastrointestinal tract of piglets. ACS Omega 2020, 5, 5241-5248. [CrossRef]

30. Beier, R.C.; Petrujkić, B.T.; Sedej, I.J.; Anderson, R.C.; Nedeljković, T.J.; Nisbet, D.J. Thymol depletion in the pig stomach. In Proceedings of the Abstracts at the 6th Central European Food Congress (CEFOOD 2012), Novi Sad, Serbia, 23-26 May 2012; p. 49.

31. Petrujkić, B.; Nisbet, D.J.; Levent, G.; He, H.; Genovese, K.J.; Anderson, R.C.; Beier, R.C.; Harvey, R.B. Lipid-caused antagonism of the bactericidal activity of thymol and thymol- $\beta$-D-glucopyranoside is not overcome by emulsifiers. Safe Pork 2019, 13, 127-128. Available online: https://www.iastatedigitalpress.com/safepork/article/id/11221/ (accessed on 28 February 2021).

32. Wilfart, A.; Montagne, L.; Simmins, H.; Noblet, J.; van Milgen, J. Digesta transit in different segments of the gastrointestinal tract of pigs as affected by insoluble fibre supplied by wheat bran. Br. J. Nutr. 2007, 98, 54-62. [CrossRef] 